E International

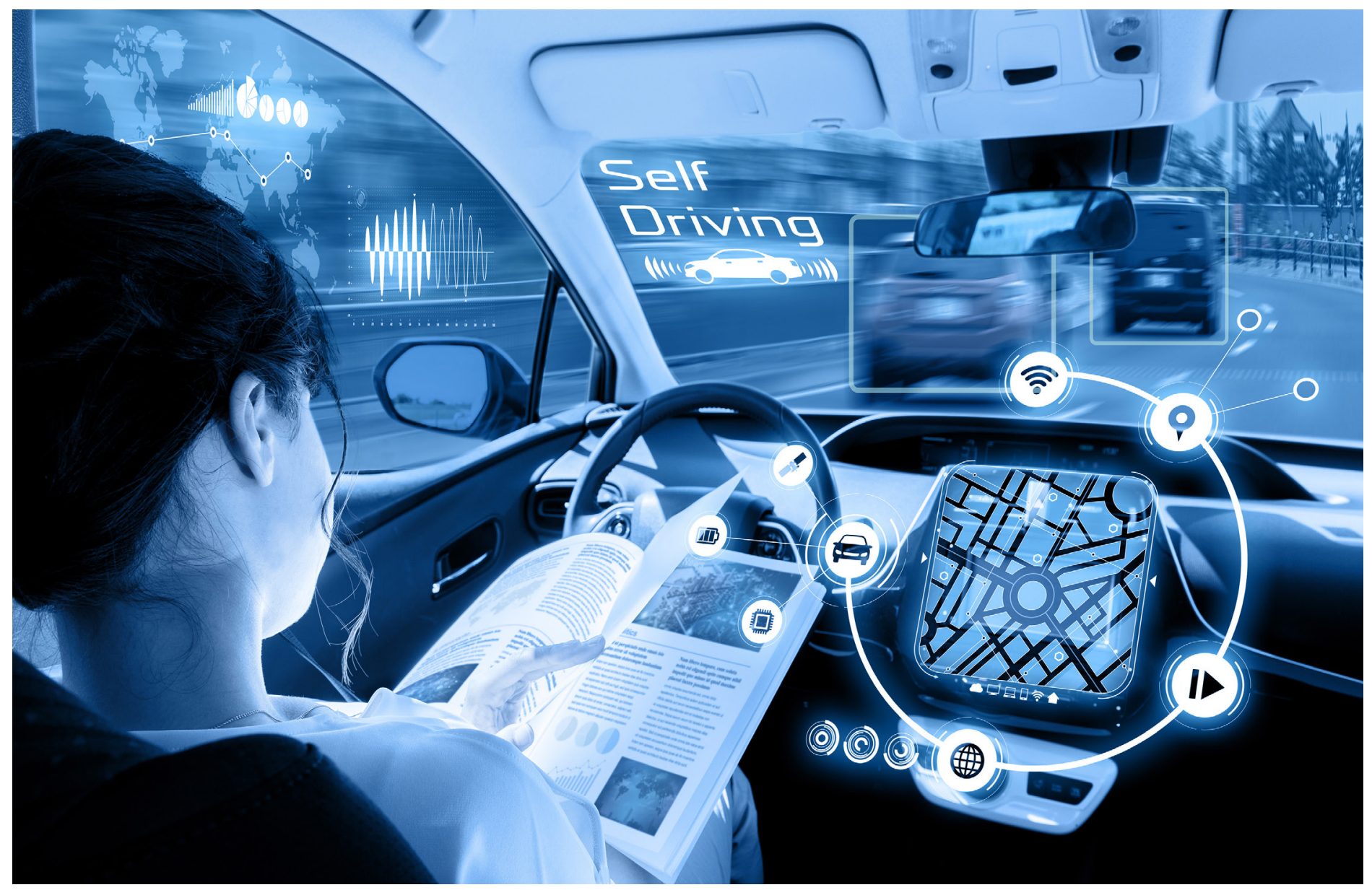

\title{
Influence of ICT on
}

Public Transport Use

and Behaviour in Seoul

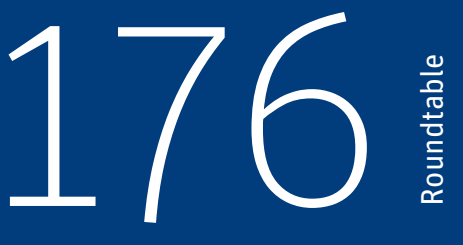

Discussion Paper

Sungwon Lee

Gyeng Chul Kim

Seung Kook Wu

Jieun $\mathrm{Oh}$ 


\section{Influence of ICT on Public Transport Use and Behaviour in Seoul Discussion Paper}

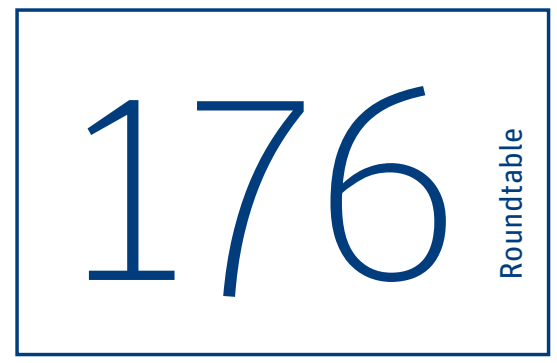

Sungwon Lee

Gyeng Chul Kim

Seung Kook Wu

Jieun $\mathrm{Oh}$ 


\title{
The International Transport Forum
}

The International Transport Forum is an intergovernmental organisation with 59 member countries. It acts as a think tank for transport policy and organises the Annual Summit of transport ministers. ITF is the only global body that covers all transport modes. The ITF is politically autonomous and administratively integrated with the OECD.

The ITF works for transport policies that improve peoples' lives. Our mission is to foster a deeper understanding of the role of transport in economic growth, environmental sustainability and social inclusion and to raise the public profile of transport policy.

The ITF organises global dialogue for better transport. We act as a platform for discussion and prenegotiation of policy issues across all transport modes. We analyse trends, share knowledge and promote exchange among transport decision-makers and civil society. The ITF's Annual Summit is the world's largest gathering of transport ministers and the leading global platform for dialogue on transport policy.

The Members of the Forum are: Albania, Armenia, Argentina, Australia, Austria, Azerbaijan, Belarus, Belgium, Bosnia and Herzegovina, Bulgaria, Canada, Chile, China (People's Republic of), Croatia, Czech Republic, Denmark, Estonia, Finland, France, Former Yugoslav Republic of Macedonia, Georgia, Germany, Greece, Hungary, Iceland, India, Ireland, Israel, Italy, Japan, Kazakhstan, Korea, Latvia, Liechtenstein, Lithuania, Luxembourg, Malta, Mexico, Republic of Moldova, Montenegro, Morocco, the Netherlands, New Zealand, Norway, Poland, Portugal, Romania, Russian Federation, Serbia, Slovak Republic, Slovenia, Spain, Sweden, Switzerland, Turkey, Ukraine, the United Arab Emirates, the United Kingdom and the United States.

\author{
International Transport Forum \\ 2 rue André Pascal \\ F-75775 Paris Cedex 16 \\ contact@itf-oecd.org \\ www.itf-oecd.org
}

\section{ITF Discussion Papers}

ITF Discussion Papers make economic research, commissioned or carried out in-house at ITF, available to researchers and practitioners. They describe preliminary results or research in progress by the author(s) and are published to stimulate discussion on a broad range of issues on which the ITF works. Any findings, interpretations and conclusions expressed herein are those of the authors and do not necessarily reflect the views of the International Transport Forum or the OECD. Neither the OECD, ITF nor the authors guarantee the accuracy of any data or other information contained in this publication and accept no responsibility whatsoever for any consequence of their use. This document and any map included herein are without prejudice to the status of or sovereignty over any territory, to the delimitation of international frontiers and boundaries and to the name of any territory, city or area. Comments on Discussion Papers are welcome.

Cite this work as: Lee et al. (2019), "Influence of ICT on Public Transport Use and Behaviour in Seoul", International Transport Forum Discussion Papers, No. 2019/02, OECD Publishing, Paris. 


\section{Table of contents}

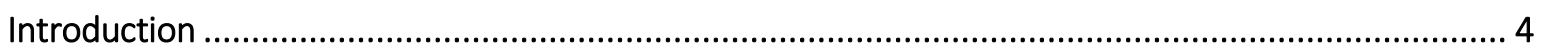

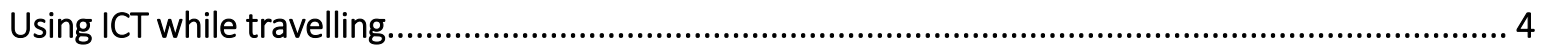

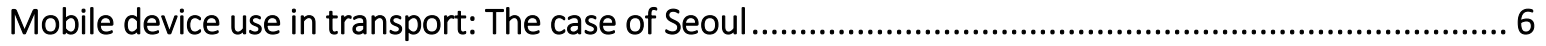

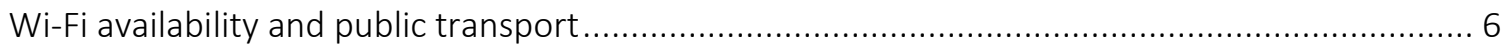

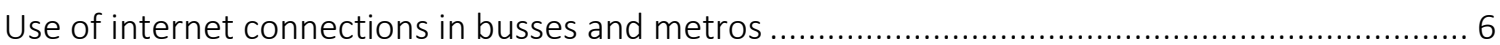

Influence of ICT amenities on mode choices: An analysis of stated preferences............................... 8

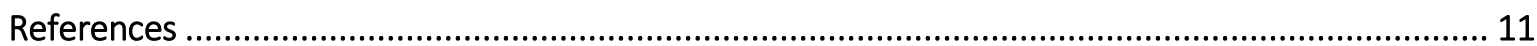




\section{Introduction}

One of the most salient characteristics of the 21st century has been the unprecedented advances in information and communication technology (ICT). Today, mobile devices and Wi-Fi have become ubiquitous in most cities in Korea to the degree that many modes of public transport, such as subways and buses, now offer free Wi-Fi services to passengers. Korea's population is just over 50 million, yet there are more than 58 million mobile phone subscriptions in the city.

This paper considers how the advances in ICT have brought fundamental behavioural changes toward mass transit in Seoul, Korea. In the past, mass transit had been regarded as inferior to private transport. Today, though, many Seoul residents give preference to public transport over private. This shift may be due in part to a combination of improved frequency in mass transit services and the amenities such services provide. The enhanced $\mathrm{Wi}$-Fi facilities make it possible for travellers to use their mobile devices to conduct a range of activities, both personal and professional, while travelling.

\section{Using ICT while travelling}

Historically, travel time has been treated as a disutility and a cost to be minimised (Frei and Mahmassani, 2011; Banerjee and Kanafani, 2008). Those who wish to use their time productively tend to have lower utility for travel (Ory and Mokhtarian, 2005). As travel time saving is often the greatest benefit of new road projects, investment in those geared towards shortening travel time is easily justified. When choosing a mode of transport, travellers may still see environmentally conscious and less costly options, such as public transport, walking and cycling, as inferior because of longer travel times. Today, though, the utility of travel time is being re-evaluated.

An estimated 4.5 billion people were using mobile phones worldwide in 2014 (eMarketer, 2014). This number will rise as mobile phone use increases in the Middle East, Africa, Asia-Pacific and other regions. This change is not only about a substantial increase in the number of mobile phone users, but also about the rapid adoption of smartphone technologies as these devices become more affordable and better supported by their network infrastructures. Advances in and adoption of smart ICT devices and technologies can improve people's daily lives by enabling easy access to a range of on-demand goods or services, allowing users to manage their work or domestic arrangements while travelling. This challenges the traditional view of travel time as a disutility (Lyons and Urry, 2005), especially on public transit.

On the other hand, Lee-Gosselin and Miranda-Moreno (2009) argue that the use of ICT may fragment people's daily activities. People no longer need to be in one place, be that a work place or a home, to meet their activity needs. Working, shopping, paying bills and a multitude of other activities can now be done "on the move". This fragmentation has resulted in an increased demand for mobility. For example, Lee-Gosselin and Miranda-Moreno cite a panel survey of data collected in Quebec from 2000 to 2006 showing that mobile phone users tend to travel more often and have more out-of-home activities than non-users. 
Train passengers who have access to Wi-Fi can receive and answer e-mails, play games, obtain travel advice in real time and listen to music. These activities can make train travel less stressful (Frei and Mahmassani, 2011). It is not surprising, then, that the availability of Wi-Fi can influence the choice of transport mode. A 2007 Scottish survey found that 64\% of travellers said that Wi-Fi influenced their mode choice. Almost one in five (19\%) Wi-Fi users preferred travel by train than by plane because of the availability of Wi-Fi (Accent, cited in Kay, Green and Dibb, 2010). Similar preferences in favour of train travel over air travel were also found in Korea (Kim and Choi, 2011; Hong, 2012). Overall, "the ability to stay connected and turn travel time into productive work time can be a significant attraction for business travellers" (Kay, Green and Dibb, 2010).

Advances in ICT technology and reduced provision costs have resulted in an increase in Wi-Fi provision by public transport service providers, enabling passengers to "stay connected" while in transit. Together with more convenient online ticketing services, public transport has become a more attractive transport option than in the past. Connolly, Caulfield and O'Mahony (2009) investigated the potential benefits of rolling stock equipped with Wi-Fi accessibility using a 2008 stated preference survey of Dublin-Ballina train passengers. They found that multitasking was extremely common among train passengers. A majority of respondents stated that they participated in two or more activities, such as mobile phone use, listening to music, reading or eating and drinking while travelling. The most common multitasking typically requires the use of mobile phones. In addition, the level of laptop and smartphone use is typically higher when there is Wi-Fi connection.

Banerjee and Kanafani (2008) examined the value of wireless internet connections on trains. They modelled the Value of Time using an efficiency factor that represented the ratio of the efficiency of working while in transit to that of working in other places (i.e. the efficiency factor becomes one if working while in transit is as efficient as working in an office). Using historical ridership data from the Capitol Corridor Joint Project Authority from September 2004 to March 2005, Banerjee and Kanafani found that combining work with travel increases the utility of riders and reduces the value placed on travel time. Therefore, riders are willing to pay more for longer trips if there is opportunity for carrying out productive work. Based on the results from their model, Banerjee and Kanafani argue that having a "mobile office" could change how riders value travel time and that they may begin to place more value on comfort and convenience of travel over the speed of travel. As a result, the demand for train services, as well as for comfort and other attributes that make time use on train possible, will also increase.

Gamberini et al. (2012) found that train passengers are equally likely to engage in multiple activities, especially those using mobile ICT devices, even for relatively short journeys. The authors state that, according to the London Underground Customer Service Centre, an average trip length on the London Underground is 22.5 minutes. This includes the time spent on board and transfer time. The authors observed the activities carried out by short-journey passengers while in the underground (with travel durations up to six stops) and found ICT device use was the most frequently engaged activity, at $26.4 \%$. The second-most frequently observed activity was a collection of activities referred as "other activities" that do not belong to any pre-defined categories. Some of these include technology use, talking with other people, reading, eating and sleeping.

Autonomous vehicles free drivers from the burden of controlling their vehicles and provide another environment for productive use of travel time. This will in turn result in a different interpretation of travel time and, hence, the value of travel time savings. For example, the value of travel time in autonomous vehicles equipped with an office interior is lower than that in conventional vehicles, according to an online stated preference survey conducted by Delft University researchers in the Netherlands (de Looff et al., 2018). 
Access to a mobile network while in transit makes travelling more productive and enjoyable, and less stressful. Connected ICT will continue to affect travellers' behaviour as well as their perception of the time spent travelling, especially with the increasing availability and uptake of autonomous vehicles.

\section{Mobile device use in transport: The case of Seoul}

\section{Wi-Fi availability and public transport}

Seoul has long been a connected and integrated city. There were more registered mobile phones (27 million) than the total population (20 million) in the Seoul Metropolitan Area as far back as 2011 (Korea Association for ICT Promotion, 2012).

There are three major mobile phone service providers in Korea: SK Telecom (SKT), Korea Telecom (KT) and LG U Plus. The latter two are actively expanding their Wi-Fi coverage in public transport services. Many modes of public transport in Seoul now provide free Wi-Fi services, though the coverage of such services admittedly remains limited. Most of the more than 500 metro stations and metro rolling stock in Seoul provide free $\mathrm{Wi}-\mathrm{Fi}$; SKT and KT are the main providers of this service in the metro. The operators of the express bus lines connecting Seoul with Gyeonggi-Do, a suburban province surrounding Seoul, have free Wi-Fi access on their buses. So do 25 bus lines in Incheon, a city bordering Seoul to the west.

The Korea Train Express (KTX), an express inter-city train service, offers laptop rental to train travellers in KX stations and has equipped two cars in each train with free laptop loan service. KTX already provides free Wi-Fi connection on its trains and its newer cars offer free use of charging sockets for mobile devices at their seats.

Nearly half of Seoul's mobile phone owners use public transport every day (Korea Transport Institute, 2013). In 2017, around 97\% of internet users accessed wireless internet, such as 3G/LTE, on mobile phones (KISA, 2017). The potential impact of ICT on riders' time use and travel behaviour could thus be quite profound.

\section{Use of internet connections in busses and metros}

The Korea Transport Institute conducted a survey of 240 public transport users (of which 219 were ICT smart device users) to better understand the level of mobile phone use in the Seoul metropolitan area's mass transit services. The survey, which has not been published, showed that over $90 \%$ of the respondents were well aware or had heard of Wi-Fi availability on public transport (Table 1). Over half of the respondents stated that they always use Wi-Fi and another $38 \%$ use the Wi-Fi occasionally. 
Table 1. Internet use on public transport

\begin{tabular}{|l|l|l|}
\hline Awareness of in-vehicle Wi-Fi availability & Number of respondents & Percentage of Respondents \\
\hline Know well & 143 & 59.6 \\
\hline Heard of & 78 & 32.5 \\
\hline Do not know & 19 & 7.9 \\
\hline Wi-Fi usage frequency & & \\
\hline Always & 129 & 53.8 \\
\hline Occasionally & 90 & 37.5 \\
\hline Never & 21 & 8.7 \\
\hline Network service (ICT device users) & & \\
\hline 3G & 33 & 15.1 \\
\hline 4G (LTE) & 134 & 61.2 \\
\hline Wi-Fi & 52 & 23.7 \\
\hline
\end{tabular}

Approximately $40 \%$ of the 219 transit users with ICT devices who used mainly $3 G$ and $4 \mathrm{G}$ had access to sufficient data allowances (Table 2) and so were less compelled to use Wi-Fi while in transit. However, the majority of Wi-Fi users found the Wi-Fi connection to be insufficient or inconsistent (Table 3). It may be useful to monitor the trend in the proportion of travellers using Wi-Fi, if only to justify improvements in Wi-Fi connection or improve the overall experience of these mass transit travellers.

Table 2. Reasons for not using Wi-Fi on public transport in the Seoul metropolitan area

\begin{tabular}{|l|l|l|}
\hline Reason & Number of respondents & Percentage of Respondents \\
\hline Inconsistent (frequent loss of connection) & 71 & 42.5 \\
\hline Limitless data with own service provider & 34 & 20.4 \\
\hline Not sensitive to data use (minimal data use) & 32 & 19.1 \\
\hline Inconvenience of connecting to Wi-Fi & 26 & 15.6 \\
\hline Unknown Wi-Fi availability & 2 & 1.2 \\
\hline Slow speed & 1 & 0.6 \\
\hline Other & 1 & 0.6 \\
\hline
\end{tabular}

Note: $1673 \mathrm{G}$ and $4 \mathrm{G}$ network users responded to this survey.

Table 3 . Perception of Wi-Fi quality in transit vehicles

\begin{tabular}{|l|l|l|}
\hline Perception & Number of respondents & Percentage of Respondents \\
\hline Good connection and consistent signal & 8 & 15.4 \\
\hline Good connection but frequent loss of signal & 32 & 61.5 \\
\hline Bad connection & 12 & 23.1 \\
\hline
\end{tabular}

Note: The total number of Wi-Fi user respondents was 52.

Table 4 tabulates the distribution of respondents by their monthly data allowance. Of all respondents, $67 \%$ have access to more than one Gigabyte (GB) of monthly data, leaving only one-third with access to less. Assuming that $1 \mathrm{~GB}$ of data allowance is sufficient to conduct multiple tasks while travelling, affordable data plans offered by network providers may explain the diminishing role free Wi-Fi plays in the choice of public transport modes. 
Table 4 . Amount of free data provided monthly

\begin{tabular}{|l|l|l|}
\hline Amount & Number of respondents & Percentage of Respondents \\
\hline$<1 G B$ & 79 & 32.9 \\
\hline $1-2 G B$ & 58 & 24.2 \\
\hline $2-3 G B$ & 15 & 6.3 \\
\hline $3-4 G B$ & 3 & 1.2 \\
\hline$>4 G B$ & 85 & 35.4 \\
\hline
\end{tabular}

Note: The average amount of free monthly data of respondents is $3.25 \mathrm{~GB}$.

With over $70 \%$ of respondents using mobile phones for at least one hour a day (Table 5), it is helpful to understand the purpose of use. Browsing the internet (59\%) and texting (57\%) were the top two purposes of internet use while in transit (Table 6). In addition, one-fifth and more than one-quarter played games or conducted business tasks respectively.

Table 5 . Daily mobile phone use

\begin{tabular}{|l|l|l|}
\hline Average time & Number of respondents & Percentage of Respondents \\
\hline Less than 30 min & 19 & 7.9 \\
\hline 30 min to 1 hour & 45 & 18.8 \\
\hline 1 hour to 2 hours & 55 & 22.8 \\
\hline 2 hours to 3 hours & 53 & 22.1 \\
\hline 3 hours to 5 hours & 41 & 17.1 \\
\hline More than 5 hours & 27 & 11.3 \\
\hline
\end{tabular}

Table 6 . Purpose of internet connection in transit vehicles

\begin{tabular}{|l|l|l|}
\hline Purpose & Number of respondents & Percentage of Respondents \\
\hline Internet search & 142 & 59.2 \\
\hline Texting & 136 & 56.7 \\
\hline Business & 67 & 27.9 \\
\hline Game & 48 & 20.0 \\
\hline Media & 29 & 12.1 \\
\hline Social networks & 16 & 6.7 \\
\hline
\end{tabular}

Note: The total number of responses exceeds the 219 people surveyed as some respondents conduct more than one activity while travelling.

\section{Influence of ICT amenities on mode choices: An analysis of stated preferences}

In 2014, 240 Seoul car users were asked about their choice of transport mode in a stated preference survey. They were presented with a hypothetical scenario in which ICT amenities in public transport were increasingly available. The survey obtained a total of 4228 effective data points from a range of choice 
questions. To model the survey results, the analysis assumed the following utility functions for the use of car and mass transit (e.g. bus or subway):

$$
\begin{gathered}
U_{\text {car }}=\propto+\beta_{1} C_{\text {fuel }}+\beta_{2} C_{\text {time }} \\
U_{\text {mass }}=\beta_{3} M_{\text {ict }}+\beta_{4} M_{\text {time }}
\end{gathered}
$$

where car = original mode of passenger car; mass = public transport; $C_{\text {fuel }}=$ fuel price, $C_{\text {time }}=$ private vehicle in-vehicle time; $M_{\text {ict }}=$ level of ICT services in public transport; $M_{\text {time }}=$ in-vehicle time of public transport; $\alpha$ is the constant term for private passenger vehicle utility function representing the intrinsic benefits of car use and $\beta$ s are the coefficient estimates for the explanatory variables. In addition to travel cost and time attributes, the model has $\mathrm{M}_{\text {ict }}$ to represent the level of Wi-Fi service in either buses or subways. This attribute has three ICT connection levels - good, average and no connection. The questionnaire separated the sample into two sub-groups: car users who used either the bus or the subway as an alternative mode of transport.

As fuel price and private vehicle in-vehicle time rise, the utility of using a car is expected to decrease. Therefore, the corresponding coefficient estimates should have negative signs. Similarly, the coefficient estimate for in-vehicle time of public transport is also expected to be negative but positive for the level of ICT services in public transport.

Table 7 tabulates the model results for car users indicating they used bus or subway as an alternate mode respectively. All the coefficients for the explanatory variables in both models were statistically significant at the $1 \%$ level and have the above expected signs. The relative size of the coefficients suggests respondents were more sensitive to travel time changes than to fuel price changes. This is not surprising given that fuel price is only one of the cost components that influence the cost of driving. The constant term was statistically insignificant in both models. This contradicts many previous studies which typically found this coefficient of the intrinsic benefits of car use to be positive and statistically significant. This indicates that the possibility for users to perform work and non-work activities while travelling due to free $\mathrm{Wi-Fi}$ amenities might have lessened the intrinsic benefits (e.g. privacy and comfort) from using private cars over other modes.

Table 7. Coefficient estimates for users with different alternative modes

\begin{tabular}{|l|c|c|c|c|}
\hline \multirow{2}{*}{} & \multicolumn{2}{|c|}{ Bus as an alternative mode } & \multicolumn{2}{c|}{ Subway as an alternative mode } \\
\cline { 2 - 5 } & Coefficient & Standard Error & Coefficient & Standard Error \\
\hline$\alpha$ & 0.25930 & 0.17834 & -0.11309 & 0.18785 \\
\hline $\mathrm{C}_{\text {fuel }}$ & $-0.14258 \mathrm{E}-05^{*}$ & $0.4319 E-06$ & $-0.94589 \mathrm{E}-06^{*}$ & $0.3209 E-06$ \\
\hline $\mathrm{C}_{\text {time }}$ & $-0.04316^{*}$ & 0.00761 & $-0.02434^{*}$ & 0.00530 \\
\hline $\mathrm{M}_{\text {ict }}$ & $0.33463^{*}$ & 0.06910 & $0.23738^{*}$ & 0.06988 \\
\hline $\mathrm{M}_{\text {time }}$ & $-0.04156^{*}$ & 0.00666 & $-0.02399^{*}$ & 0.00463 \\
\hline
\end{tabular}

* $1 \%$ statistical significance.

Note: Sample size is 1920.

Table 8 shows similar modelling results for users with different alternate modes, using the coefficient estimates to calculate own and cross elasticities. Consistent with findings from similar studies, car users were found to be more sensitive to time-related variables than they were to fuel price variables. The demand for transport with respect to ICT service was estimated as being moderately elastic. The ICT elasticity estimates are larger than the cost elasticity estimates but smaller than the time-related elasticities, the positive estimate indicating a potential role for the provision of ICT to positively influence public transport patronage. 
Table 8. Own and cross elasticity estimates for users with different alternative modes

\begin{tabular}{|l|c|c|c|c|}
\hline & \multicolumn{2}{|c|}{ Bus as an alternative mode } & \multicolumn{2}{c|}{ Subway as an alternative mode } \\
\hline User type & Car & Mass & Car & Mass \\
\hline$C_{\text {fuel }}$ & -0.2036 & 0.1069 & -0.1976 & 0.0902 \\
\hline$C_{\text {time }}$ & -1.0322 & 0.5769 & -0.9036 & 0.4363 \\
\hline$M_{\text {ict }}$ & -0.4390 & 0.2302 & -0.3245 & 0.1502 \\
\hline$M_{\text {time }}$ & 1.0965 & -0.6464 & 0.9875 & -0.4979 \\
\hline
\end{tabular}

Other conclusions that can be drawn include:

- Every $10 \%$ increase in fuel cost is expected to reduce demand for car travel by around $2 \%$ and increase mass transit uses by around $1 \%$.

- Every $10 \%$ increase in in-vehicle travel time is expected to result in a $9 \%$ to $10 \%$ reduction in the demand for car travel but only between $4.3 \%$ and $5.7 \%$ increase in mass transit uses.

- The overall change in ICT services (from no connection to average or from average to good connection) is expected to reduce demand for car travel by between $32 \%$ and $44 \%$, and increase the demand for mass transit by between $15 \%$ and $23 \%$.

- Every $10 \%$ increase in in-vehicle travel time on mass transit is expected to reduce its demand by $5 \%$ to $6 \%$ and a nearly proportionate increase in the demand for car travel. 


\section{References}

Banerjee, I. and A. Kanafani (2008), The Value of Wireless Internet Connection on Trains: Implications for Mode-Choice Models, Working Papers, University of California Transport Center.

Connolly, D., B. Caulfield, and M. O'Mahony (2009), "Rail Passengers' Preferences for Onboard Wi-Fi Internet Access", presented at the $88^{\text {th }}$ Annual Meeting of the Transportation Research Board, Washington, DC.

De Looff, Erwin., G. H. de Almeida Correia, S. van Cranenburgh, M. Snelder, and B. van Arem (2018), Potential Changes in Value of Travel Time as a Result of Vehicle Automation: a Case-Study in the Netherlands, presented at the $97^{\text {th }}$ Annual Meeting of the Transportation Research Board, Washington, DC, available for order at https://trid.trb.org/view/1495608.

eMarketer, Smartphone Users Worldwide Will Total 1.75 Billion in 2014, http://www.emarketer.com/Article/Smartphone-Users-Worldwide-Will-Total-175-Billion-2014/1010536 (accessed April 2014).

Frei, C. and H. S. Mahmassani (2011), "Private Time on Public Transit: Dimensions of Information and Telecommunication Use of Chicago Transport Riders", Transportation Chicago Conference, http://www.transportchicago.org/uploads/5/7/2/0/5720074/frei tc website posting.pdf.

Gamberini, L., A. Spagnolli, A. Miotto, E. Ferrari, N. Corradi, and S. Furlan (2013), “Passengers' activities during short trips on the London Underground", Transportation, vol 40/2, pp.251-268, DOI 10.1007/s11116-012-9419-4.

Hong, D. (2012), A Study of the Factors Affecting the User Satisfactions of Express Railway, Hanyang University, Seoul, http://dcollection.hanyang.ac.kr/public resource/pdf/000000063368 20190206004511.pdf.

Kay, D., J. Green and S. Dibb (2010), "Smarter Moves: How information communications technology can promote sustainable mobility", Sustainable Development Commission,

www.sd-commission.org.uk/publications.php@id=1050.html.

Kim, J. and S. Choi (2011), "Transit Ridership Increase by mobile ICT devices", Monthly Land Magazine, vol. 351, Korean Research Institute for Human Settlements, http://library.krihs.re.kr/dl image/IMG/05/000000020028/SERVICE/000000020028 01.PDF.

Korea Association for ICT Promotion (2012), Statistics Book on Broadcasting and Telecommunication Industry 2012, https://www.kait.or.kr/work/stat_board_pop.jsp?b_id=109\&url=1.

Korea Internet and Security Agency (KISA) (2017), Korea 2018 Internet White Paper, https://www.kisa.or.kr/isp/common/downloadAction.jsp?bno=263\&dno=6\&fseq=2.

Korea Transport Institute (2013), Korea Transport DB Building Project, Travel Movement and Mode Share Survey and Analysis, https://www.ktdb.go.kr/www/selectPblcteWebList.do?key=37\&searchLclasCode=P BLO1.

Lee-Gosselin, M. and L. Miranda-Moreno (2009), "What is Different About Urban Activities of Those with Access to ICT? Some early evidence from Quebec, Canada", Journal of Transport Geography, Vol. 17/2, pp. 104-114, https://doi.org/10.1016/i.jtrangeo.2008.11.009. 
Lyons, G. and J. Urry (2005), "Travel Time in the Information Age", Transportation Research Part A, Vol. 39, pp. 257-276, https://doi.org/10.1016/i.tra.2004.09.004.

Ory, D. and P. Mokhtarian (2005), "When is Getting There Half the Fun? Modeling the liking for travel", Transportation Research Part A, Vol. 39/2-3, pp. 97-123, https://doi.org/10.1016/i.tra.2004.09.006.

Sawers, P. (2017), "5 Billion People Now Have a Mobile Phone Connection, According to GSMA Data", venturebeat.com, venturebeat.com/2017/06/13/5-billion-people-now-have-a-mobile-phoneconnection-according-to-gsma-data/, (accessed August 2018). 


\section{EInternational Transport Forum}

\section{Influence of ICT on Public Transport Use and Behaviour in Seoul}

This paper explores the impact that advances in Information and Communication Technology (ICT) have on the behaviour of transport users and their mode choice habits in Seoul. It discusses the stated preference survey conducted in Seoul and the analysis carried out using the discrete choice modelling approach to understand the sensitivity of the demand for private and public transport uses on time, cost and availability of ICT.

All resources from the Roundtable on Zero Value of Time are available at: www.itf-oecd.org/zero-value-time-roundtable. 